\title{
Occupational exposure to formaldehyde and histopathological changes in the nasal mucosa
}

\author{
C EDLING,' H HELLQUIST, ${ }^{2}$ L ÖDKVIST ${ }^{3}$ \\ From the Department of Occupational Medicine, 'at University Hospital, S-751 85 Uppsala, and University \\ Hospital, Linköping, Sweden, College of Medicine, ${ }^{2}$ King Saud University, Abha, Saudi Arabia, and Department \\ of Otorhinolaryngology, ${ }^{3}$ University Hospital, Linköping, Sweden
}

\begin{abstract}
To study the cytotoxic effect of formaldehyde on the human nasal mucosa 75 men with occupational exposure to formaldehyde or to formaldehyde and wood dust, were examined, looking particularly at early signs of irritative effects and histopathological changes in the nasal mucosa. All men underwent a medical examination and a nasal biopsy specimen was examined by a pathologist and graded from 0-8 according to the morphological changes. A high frequency of nasal symptoms, mostly a running nose and crusting, was related to exposure to formaldehyde. Only three men had a normal mucosa; the remainder had loss of cilia and goblet cell hyperplasia $(11 \%)$ and squamous metaplasia (78\%); in six cases $(8 \%)$ there was a mild dysplasia. The histological grading showed a significantly higher score when compared with unexposed contents $(2.9 v 1.8)$. There was no dose response relation, no malignancies, and no difference in the histological score between those exposed to formaldehyde or to formaldehyde and wood dust.
\end{abstract}

Formaldehyde is a widely used chemical, primarily in the production of specific resins although it is also used in a variety of other industries and professions, including hospitals and dentistry. ${ }^{1-3}$ Well known toxic effects of exposure to formaldehyde are irritation of mucous membranes and allergic sensitisation of the skin. During the past few years, some controversy has arisen over the possible risk of human cancer posed by exposure to formaldehyde. After long term exposure, mutagenic effects have been shown in vitro ${ }^{45}$ and carcinogenic effects in experimental animals. ${ }^{68}$

In view of the finding of squamous cell carcinoma in the nasal cavity of rats and mice exposed to formaldehyde, several epidemiological studies have been undertaken. In some studies an increased risk of cancer has been observed in jobs involving exposure to formaldehyde. ${ }^{9-17}$ Other studies, however, have failed to show such an association. ${ }^{18-20}$

When discussing a possible risk of cancer not only is the endpoint of interest but also the possibility of the early detection of any precancerous lesions. Most authors consider that cancer caused by exposure to formaldehyde is unlikely in sites other than those in direct contact with the gas. Studies showing an increase of nasal carcinoma among rodents have also shown dose dependent and reversible changes on the

Accepted 21 September 1987 nasal mucosa such as rhinitis, epithelial dysplasia, and squamous metaplasia. Some of these irritative effects may be regarded as precancerous lesions and therefore be an early sign of exposure to a carcinogen. ${ }^{21}$

We have studied 75 men occupationally exposed to formaldehyde to look for early signs of irritative effects on the nasal mucosa. Some preliminary results of these studies have already been published. ${ }^{22} 23$

\section{Subjects and methods}

All 104 male workers at three different plants, two processing particle boards, and one laminae, and with occupational exposure to formaldehyde were invited to take part in the study. Those accepting the invitation $(72 \%)$ underwent a medical examination, which included a nasal biopsy.

By taking a careful history, the exposure time, past diseases, the duration and intensity of different symptoms relating to the respiratory tract and their relation to workplace exposure, and smoking habits were noted. Changes from normal were evaluated in a clinical examination of the nose and nasopharynx.

Biopsy specimens with a diameter of $2 \mathrm{~mm}$ were taken with forceps under local anaesthesia $1 \mathrm{~cm}$ behind the anterior edge of the inferior turbinate. The specimens were fixed in $10 \%$ neutral buffered formalin and embedded in paraffin, cut at various levels, and stained with haematoxylin and eosin. The sections, 


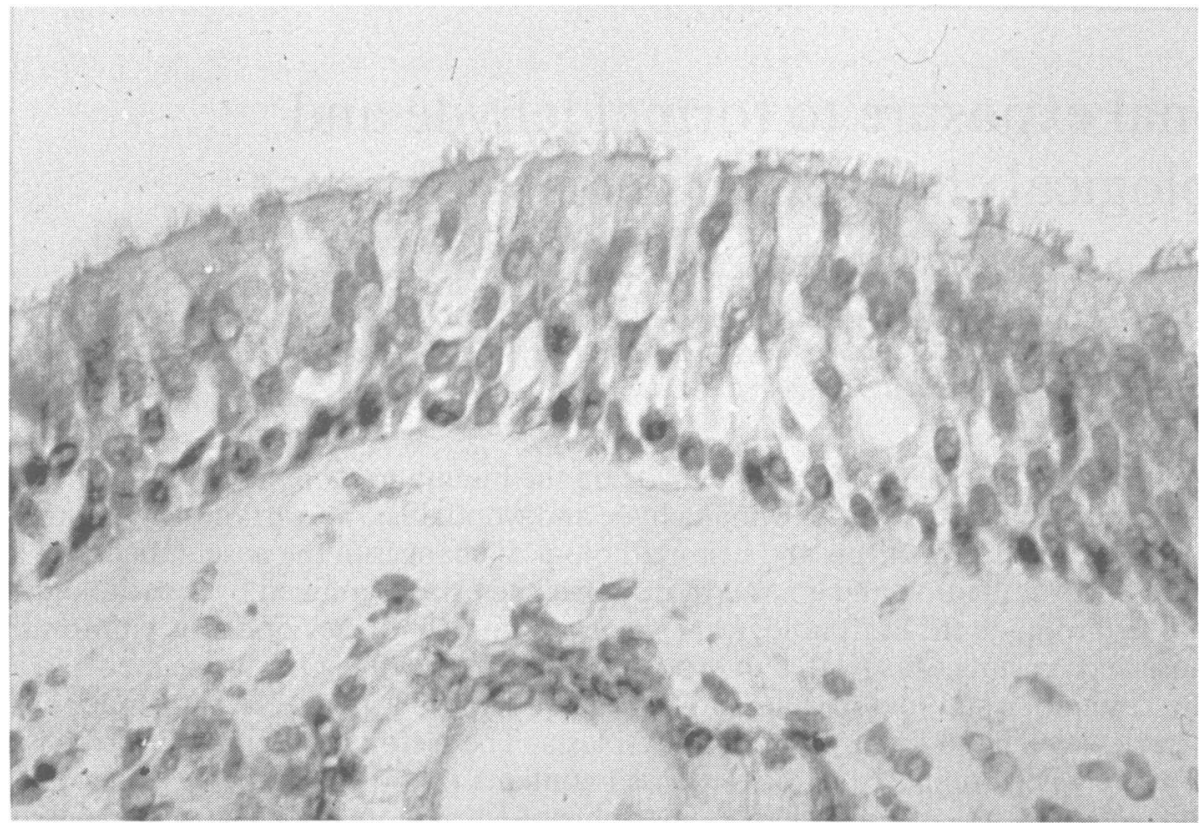

Fig 1 Nasal

mucosa showing

normal cylindric

cells with cilia.

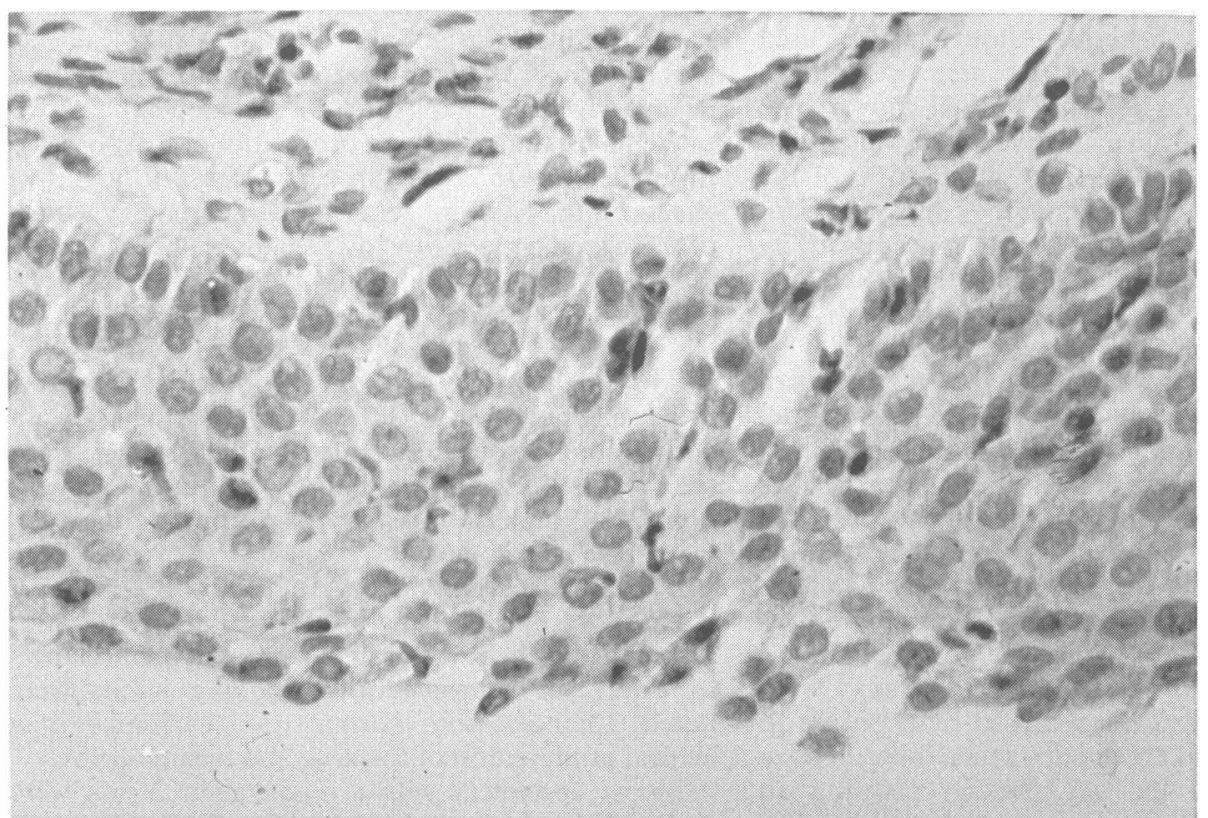

Fig 2 Nasal mucosa showing metaplasia where normal cylindric cells have been replaced and there are no cilia. $\vec{\varphi}$

응 ®

웅

을 
Table 1 Histological characteristics and scores used for grading the nasal mucosa

\begin{tabular}{ll}
\hline Histological characteristics & Point score \\
\hline Normal respiratory epithelium & 0 \\
Loss of ciliated cells & 1 \\
Mixed cuboid/squamous epithelium, metaplasia & 2 \\
Stratified squamous epithelium & 3 \\
Keratosis & 4 \\
"Budding" of epithelium & 1 \\
Mild or moderate dysplasia & 6 \\
Severe dysplasia & 7 \\
Carcinoma & 8 \\
\hline
\end{tabular}

with covered labels, were examined twice by the pathologist with an interval of three weeks and without access to clinical or occupational information. The morphological grading was carried out using the system proposed by Torjussen et al ${ }^{24}$ (table 1).

The histological findings were compared with a referent group of 25 men, selected with regard to age and smoking habits but with no industrial exposure to formaldehyde.

The differences in histological score between the groups was tested by the Wilcoxon non-parametric test.

Hygienic measurements had been made by the industrial hygienists at the three plants on different occasions between 1975 and 1983. The levels (TWA) of formaldehyde in air were in the range of $0 \cdot 1-1 \cdot 1$ $\mathrm{mg} / \mathrm{m}^{3}$, with peaks up to $5 \mathrm{mg} / \mathrm{m}^{3}$. No measurements were available before 1975 but it was estimated that the exposure levels had been somewhat higher during the 1960 s and early 1970 s. In the two plants processing particle boards the concentrations of wood dust were about $0.6-1 \cdot 1 \mathrm{mg} / \mathrm{m}^{3}$. The working places were normally ventilated and the workers used no personal protection.

\section{Results}

Seventy five men with a mean age of 38 (range 22-63)

Table 2 Number of subjects, age, exposure period, and smoking habits

\begin{tabular}{lll}
\hline & Exposed & Referents \\
\hline No & 75 & 25 \\
Age: & & \\
$\quad$ Mean & 38 & 35 \\
$\quad$ Range & $22-63$ & $25-60$ \\
$\quad$ Exposure time: & & \\
$\quad$ Mean & $10 \cdot 5$ & - \\
$\quad$ Range & $1-39$ & 12 \\
Emokers & 26 & 4 \\
Never smokers & 7 & 9 \\
\hline
\end{tabular}

Table 3 Distribution of histological score of exposed workers

\begin{tabular}{lrc}
\hline Point score & No & $\%$ \\
\hline 0 & 3 & 4 \\
1 & 8 & 11 \\
2 & 24 & 32 \\
3 & 18 & 24 \\
4 & 16 & 21 \\
5 & 0 & 0 \\
6 & 6 & 8 \\
7 & 0 & 0 \\
8 & 0 & 0 \\
\hline
\end{tabular}

and with a mean exposure to formaldehyde of $10 \cdot 5$ years (range 1-39) took part in the study. Twenty six $(35 \%)$ were smokers, seven ( $9 \%$ ) ex-smokers (stopped smoking ten years before examination), and $42(56 \%)$ had never smoked (table 2). In the referent group, aged $25-60$ (mean 35$), 12$ (48\%) were smokers, four $(10 \%)$ ex-smokers, and nine (36\%) non-smokers.

The histories disclosed a high frequency of symptoms relating to the eyes and upper airways. Nasal symptoms, mostly running nose and crusting related to the exposure to formaldehyde, were noted in $60 \%$ of the subjects; $75 \%$ complained of running eyes when exposed to formaldehyde. Twelve (16\%) mentioned a history of upper airways allergy.

Clinical examination showed a grossly normal nasal mucosa in $75 \%$ of the cases, whereas the rest of the exposed workers had swollen or dry changes or both of the nasal mucosa.

The histological examination (table 3) showed that only three of the cases had a normal, ciliated pseudostratified epithelium (fig 1). In eight there was a loss of ciliated cells and goblet cell hyperplasia, in 59 squamous metaplasia (fig 2), and in six a mild dysplasia. The histological grading showed a significantly higher score in the exposed group compared with the referents, 2.9 versus $1.8 ; p<0.05$ (Wilcoxon).

When relating the histological score to duration of exposure, the mean histological score was about the same regardless of years of employment (table 4). Ten men had been exposed to formaldehyde for more than 20 years and their average histological score was $2 \cdot 5$. The average exposure time for the six men with "mild dysplasia" was six years with no dose response relation. Exposed smokers had a higher (non-significant) score than ex-smokers and non-smokers.

To evaluate a possible combined effect of formaldehyde and wood dust on the nasal mucosa the men working in the particle board plants, and consequently exposed to both formaldehyde and wood dust, were compared with the workers from the laminae plant, exposed only to formaldehyde; no difference in the histological scores was found. 
Table 4 Average histological score of exposed workers in relation to years of employment

\begin{tabular}{lccc}
\hline & \multicolumn{3}{l}{ Employment (years) } \\
\cline { 2 - 4 } & $\leqslant 5$ & $6-10$ & $>10$ \\
\hline No of men & 23 & 28 & 24 \\
Average score & 2.7 & 2.8 & 2.9 \\
\hline
\end{tabular}

\section{Discussion}

The results of this study indicate that occupational exposure to formaldehyde in the range of $0 \cdot 1-1 \cdot 1$ $\mathrm{mg} / \mathrm{m}^{3}$ (Swedish TLV $1.0 \mathrm{mg} / \mathrm{m}^{3}$ ) may result in pathological changes in the nasal mucosa when compared with non-exposed.

The design of the study is cross sectional and since participation was voluntary and the participation rate only $72 \%$ it may possibly be that only people with symptoms from the upper airways took part - that is, there was some selection bias. On the other hand, if people with symptoms caused by the exposure leave the plant a cross sectional design will underestimate the true effect of exposure.

Most of the non-participants ( $83 \%)$ worked shifts at one of the particle board plants and were off work on the days the examination took place. At the two other plants the participation rate was about $90 \%$. To check possible selection effects we undertook a questionnaire survey among the exposed non-participating men at the particle board plant where the number of drop outs was highest $(55 \%)$. The questions were the same as those asked the other participants; the response rate was $92 \%$ and the answers showed no obvious differences in age distribution, exposure time, nasal symptoms, or smoking habits compared with the group studied at the same plant (table 5). These findings suggest that the high frequency of symptoms and histopathological changes found in this study were not due to selection bias overestimating the result.

Another explanation for the findings could be that the unexposed reference group was too healthy and

Table 5 Number of men, age, exposure period, smoking habits, and frequency of symptoms of participants and nonparticipants at one particle board plant

\begin{tabular}{lll}
\hline & Participants & Non-participants \\
\hline No & 20 & 22 \\
Age (mean) & 38 & 36 \\
Exposure time (mean) & 6 & 7 \\
Smokers (\%) & 50 & 35 \\
Ex-smokers (\%) & 36 & 45 \\
Never smokers (\%) & 14 & 20 \\
Symptoms, eyes (\%) & 73 & 85 \\
Symptoms, nose (\%) & 68 & 70 \\
Symptoms, throat (\%) & 59 & 75 \\
\hline
\end{tabular}

had an unusually low score. The average score of 1.8 , however, is higher than that of 1.3 found in the nonindustrial reference group of 45 subjects used by Torjussen et al. ${ }^{24}$ This indicates that our reference group is representative of the non-industrially exposed population.

Similar pathological changes of the nasal mucosa have earlier been reported as due to age, smoking, and various types of occupational exposures including wood dust, nickel, oil mist, solvents, and dicumylperoxide ${ }^{24-27}$ In the present study the influence of age and smoking was controlled by the similarity between the exposed and referents in this respect and occupational factors other than formaldehyde and wood dust could be ruled out. Since there were no differences in average histopathological score between the groups exposed to both formaldehyde and wood dust and the group exposed only to formaldehyde we interpreted the histopathological changes as due to exposure to formaldehyde. Blair et al have suggested that simultaneous exposure to formaldehyde and particulates may increase the risk of tumour but in this study exposure to wood dust does not seem to enhance the effect of exposure to formaldehyde.$^{28}$ Smoking may have a modifying and aggravating effect on the histological picture which is reflected in a higher mean histological score for smokers despite the same duration of exposure to formaldehyde as those who have never smoked. ${ }^{23}$

In animal experiments formaldehyde has been shown to induce nasal cancer at rather high exposure levels, $5-14 \mathrm{ppm} .^{78}$ The tumours show a sharp concentration response relation with none occurring in the 2 ppm group. At that exposure level, however, epithelial dysplasia and squamous metaplasia were found, the same histopathological changes as found in this study.

When considering the carcinogenic response to formaldehyde it has been discussed whether it is an epigenetic or a genetic reaction. The epigenetic reaction is due not to the reaction of the chemical with DNA but to the overload of the normal DNA repair mechanism. The important difference in epigenetic, as opposed to genetic, mechanisms is that in a genetic mechanism there is a potential, no matter how small, for response at any exposure level. An epigenetic mechanism, however, implies a threshold level below which there is no response. The animal data on formaldehyde toxicity suggest that it is an epigenetic agent ${ }^{29}$ and that formaldehyde induced metaplasia is an irritant response. ${ }^{30}$ This may explain why we did not find a dose response relation; the histopathological changes were of the same degree regardless of exposure time as long as it exceeded a couple of years. This is also in accordance with the animal findings that exposure to high concentrations for a few hours is 
likely to cause greater damage to the mucosa than longer exposures at lower concentrations. We have not been able to study the question of reversibility but if the effect is that of an irritant one might expect a change towards normal after the cessation of exposure.

Milder changes in the nasal mucosa lead to more or less severe symptoms but no serious illness, whereas higher degrees of alterations in the mucosa, such as dysplasia, should be considered to be precancerous. ${ }^{21}$ In a study of workers exposed to nickel, a recognised occupational nasal carcinogen, Torjussen et al found dysplasia in $22 \%$ of the exposed compared with $8 \%$ in the present study. ${ }^{24}$ In that study the workers with the longest period of employment had the highest average score.

This study indicates that dysplastic changes similar to those observed in animal studies may be present among workers exposed to low levels of formaldehyde. The present results, however, with those of the animal and epidemiological studies (cf Partanen et $\left.a^{20}\right)$ suggest that the risk of nasal cancer for man, if any, is small when exposure levels are kept well below $2 \mathrm{ppm}$. This view is further strengthened by the results from the study of 26561 industrial workers exposed to formaldehyde in the United States, where no excess mortality from cancer of the nasal cavity was found, ${ }^{28}$ although further analyses of these data have indicated a dose dependent association of nasopharyngeal cancer with exposure to formaldehyde and particulates. ${ }^{31}$

The study was supported by the Swedish Work Environment Fund.

\section{References}

1 Siegel DM, Frankos VH, Schneiderman MA. Formaldehyde risk assessment for occupationally exposed workers. Regul Toxicol Pharmacol 1983;2:355-71.

2 Rosén G, Bergström B, Ekholm U. Occupational exposure to formaldehyde in Sweden. Arbete och Hälsa 1984;50:1-25. (In Swedish with English summary.)

3 Lewis BB, Chestner SB. Formaldehyde in dentistry: a review of mutagenic and carcinogenic potential. J Am Dent Assoc 1981;103:429-34.

4 Auerbach C, Moutchen-Dahmen M, Moutchen J. Genetic and cytogenetical effects of formaldehyde and related compounds. Mutation Res 1977;39:317-62.

5 Temcharoen P, Thilly WG. Toxic and mutagenic effects of formaldehyde in salmonella typhimurium. Mutation Res 1983;119:89-93.

6 Swenberg JA, Kerns WD, Mitchell RI, Gralla EJ, Pavkov KL. Induction of squamous cell carcinomas of the rat nasal cavity by inhalation exposure to formaldehyde vapor. Cancer Res 1980;40:3398-402.

7 Albert RE, Sellakumar AR, Laskin S, Kuschner M, Nelson N, Snyder CA. Gaseous formaldehyde and hydrogen chloride induction of nasal cancer in the rat. JNCI 1982;68:597-603.
8 Kerns WD, Pavkov KL, Donofrio DJ, Gralla EJ, Swenberg JA. Carcinogenicity of formaldehyde in rats and mice after longterm inhalation exposure. Cancer Res 1983;432:4382-92.

9 Harrington JM, Shannon HS. Mortality study of pathologists and medical laboratory technicians. Br Med J 1975;iv:329-32.

10 Acheson ED, Barnes HR, Gardner MJ, Osmond C, Pannett B, Taylor CP. Formaldehyde in the British chemical industry: an occupational cohort study. Lancet 1984;ii:611-6.

11 Harrington JM, Oakes D. Mortality study of British pathologists 1974-80. Br J Ind Med 1984;41:188-91.

12 Acheson ED, Barnes HR, Gardner MJ, Osmond C, Pannett B, Taylor CP. Formaldehyde process workers and lung cancer. Lancet 1984; ii:1066-7.

13 Liebling T, Rosenman KD, Pastides H, Griffin RG, Lemeshow S. Cancer mortality among workers exposed to formaldehyde. Am J Ind Med 1984;5:423-8.

14 Marsh GM. Proportional mortality patterns among chemical plant workers exposed to formaldehyde. $\mathrm{Br} J$ Ind Med 1982;39:312-22.

15 Walrath J, Fraumeni JF. Mortality patterns among embalmers. Int J Cancer 1983;31:407-11.

16 Stayner L, Smith AB, Reeve G, et al. Proportionate mortality study of workers in the garment industry exposed to formaldehyde. Am J Ind Med 1985;7:229-40.

17 Olsen JH, Plough Jensen S, Hink M, Faurbo K, Breum NO, Jensen OM. Occupational formaldehyde exposure and increased nasal cancer risk in man. Int J Cancer 1984;34:639-44.

18 Jensen OM, Andersen SK. Lung cancer risk from formaldehyde. Lancet 1982;ii:913.

19 Levine RJ, Andjelkovich DA, Shaw LK. The mortality of Ontario undertakers and a review of formaldehyde-related mortality studies. J Occup Med 1984;26:740-6.

20 Partanen T, Kauppinen T, Nurminen M, et al. Formaldehyde exposure and respiratory and related cancers. A case-referent study among Finnish woodworkers. Scand J Work Environ Health 1985;11:409-15.

21 Boysen M, Solberg LA, Torjussen W, Poppe S, H申getveit AC. Histological changes, rhinoscopial findings and nickel concentration in plasma and urine in retired nickel workers. Acta Otolaryngol (Stockh) 1984;97:105-15.

22 Edling $\mathrm{C}$, Ödkvist L, Hellquist $\mathrm{H}$. Formaldehyde and the nasal mucosa. Br J Ind Med 1985;42:570-1.

23 Edling C, Hellquist H, Odkvist L. Occupational formaldehyde exposure and the nasal mucosa. Rhinology 1987;25:181-7.

24 Torjussen W, Solberg LA, Hфgeveit A. Histopathologic changes of nasal mucosa in nickel workers. A pilot study. Cancer 1979;44:963-74.

25 Irander K, Hellquist HB, Edling C, Odkvist LM. Upper airway problems in industrial workers exposed to oil mist. Acta Otolaryngol 1980;90:452-9.

26 Hellquist H, Irander K, Edling C, Oddkvist LM. Nasal symptoms and histopathology in a group of spray-painters. Acta Otolaryngol 1983;96:495-500.

27 Hansson HA, Petruson B. Nasal mucosa changes after acute and long-term exposure to dicumylperoxide. Acta Otolaryngol (Stockh) 1986;101:102-13.

28 Blair A, Stewart P, O'Berg M, et al. Mortality among industrial workers exposed to formaldehyde. JNCI 1986;76:1071-84.

29 Clary JJ. Risk assessment for exposure to formaldehyde. In: Gibson JE, ed. Formaldehyde toxicity. London: Hemisphere Publishing Corporation, 1983: 284-94.

30 Schreiber H, Bibbo M, Wied GL, Saccomanno G, Nettesheim P. Bronchial metaplasia as a benign or premalignant lesion. Acta Cytol 1979;23:496-503.

31 Blair A, Stewart PA, Hoover RN, et al. Cancer of the nasopharynx and oropharynx and formaldehyde exposure. JNCI 1987;78:191. 